\title{
Complement Ba Measurement
}

National Cancer Institute

\section{Source}

National Cancer Institute. Complement Ba Measurement. NCI Thesaurus. Code C135403.

The determination of the amount of $\mathrm{Ba}$ frag ment of complement factor $\mathrm{B}$ in a biological sample. 